\title{
Kinetics of oxidation of acidic amino acids by sodium N-bromobenzenesulphonamide in acid medium: A mechanistic approach
}

\author{
PUTTASWAMY* and NIRMALA VAZ \\ Department of Post-Graduate Studies in Chemistry, Central College, \\ Bangalore University, Bangalore 560 001, India \\ e-mail: nvaz@vsnl.net
}

MS received 30 October 2000; revised 27 February 2001

\begin{abstract}
Kinetics of oxidation of acidic amino acids (glutamic acid (Glu) and aspartic acid (Asp)) by sodium N-bromobenzenesulphonamide (bromamine-B or $\mathrm{BAB}$ ) has been carried out in aqueous $\mathrm{HClO}_{4}$ medium at $30^{\circ} \mathrm{C}$. The rate shows firstorder dependence each on $[\mathrm{BAB}]_{\mathrm{o}}$ and $[\text { amino acid }]_{\mathrm{o}}$ and inverse first-order on $\left[\mathrm{H}^{+}\right]$. At $\left[\mathrm{H}^{+}\right]>0.60 \mathrm{~mol} \mathrm{dm}^{-3}$, the rate levelled off indicating zero-order dependence on $\left[\mathrm{H}^{+}\right]$and, under these conditions, the rate has fractional order dependence on [amino acid]. Succinic and malonic acids have been identified as the products. Variation of ionic strength and addition of the reaction product benzenesulphonamide or halide ions had no significant effect on the reaction rate. There is positive effect of dielectric constant of the solvent. Proton inventory studies in $\mathrm{H}_{2} \mathrm{O}-\mathrm{D}_{2} \mathrm{O}$ mixtures showed the involvement of a single exchangeable proton of the $\mathrm{OH}^{-}$ion in the transition state. Kinetic investigations have revealed that the order of reactivity is Asp > Glu. The rate laws proposed and derived in agreement with experimental results are discussed.
\end{abstract}

Keywords. Acidic amino acids; bromamine-B; oxidation kinetics, acid medium.

\section{Introduction}

The chemistry of aromatic sulphonyl haloamines has evoked considerable interest, as they are sources of halonium cations, hypohalite species, and $\mathrm{N}$-anions which act both as bases and nucleophiles. The prominent members of this group are chloramine-T (CAT) and chloramine- $\mathrm{B}(\mathrm{CAB})$ and the mechanistic aspects of many of these reactions have been documented ${ }^{1-3}$. Bromamine-B (BAB; $\left.\mathrm{C}_{6} \mathrm{H}_{5} \mathrm{SO}_{2} \mathrm{NBrNa} .1 \cdot 5 \mathrm{H}_{2} \mathrm{O}\right)$ is gaining importance as a mild oxidant and is found to be a better oxidizing agent than the chloro compound. A review of literature shows that kinetic studies using this reagent are meager $^{4-6}$.

Oxidation of amino acids is of great importance both from a chemical point of view and its bearing on the mechanism of amino acids metabolism. Amino acids find a number of applications in biochemical research, metabolism, microbiology, nutrition, pharmaceuticals and fortification of foods and feeds. Generally only the amino and carboxyl functional groups in $\mathrm{RCH}\left(\mathrm{NH}_{2}\right) \mathrm{COOH}$ undergo chemical transformations while

*For correspondence 
the hydrocarbon moiety remains intact. This property is attributed to the higher reactivity of the former compared to $\mathrm{R}$. There are a few reports on the kinetics of oxidation of amino acids by chloramines ${ }^{7,8}$ while, little attention has been focused on BAB's reactions with amino acids, particularly with respect to the oxidation kinetics of acidic amino acids. In view of this, we have taken up systematic kinetic study of the oxidation of acidic amino acids namely glutamic acid and aspartic acid by BAB in acid medium to explain the mechanistic aspects of these oxidations and also to understand the active form of $\mathrm{BAB}$ in aqueous acidic medium. The results are discussed in this communication.

\section{Experimental}

Bromamine-B was prepared as reported in the literature ${ }^{9}$. Its purity was checked by iodometry and by UV, IR and NMR spectra. An aqueous solution of BAB was standardized iodometrically and stored in brown bottles to arrest photochemical deterioration.

Chromatographically pure L-glutamic acid (Glu) and L-aspartic acid (Asp) (SRL, India) were further assayed by acetous perchloric acid method ${ }^{10}$. Aqueous solutions of amino acids were prepared. All other chemicals were of Analar grade. Ionic strength of the medium was kept at a high value $\left(I=1.0 \mathrm{~mol} \mathrm{dm}^{-3}\right)$, by adding a concentrated solution of $\mathrm{NaClO}_{4}$. Heavy water $\left(\mathrm{D}_{2} \mathrm{O}, 99.2 \%\right)$ was supplied by the Bhabha Atomic Research Centre, Mumbai. Triple-distilled water was used throughout where required.

\section{$2.1 \quad$ Kinetic measurements}

The reaction was carried out under pseudo-first-order condition ([amino acid] $\gg[\mathrm{BAB}]$ ) in glass-stoppered pyrex boiling tubes whose outer surface was coated black to eliminate photochemical effects. Appropriate amounts of the amino acid and $\mathrm{NaClO}_{4}$ solutions and enough water to keep the total volume constant for all runs were taken in the tube and thermostated at $30^{\circ} \mathrm{C}$. A measured amount of $\mathrm{BAB}$ solution, also thermostated at the same temperature, was rapidly added to the mixture in the tube. The progress of the reaction was monitored up to two half-lives by iodometric determination of unreacted $\mathrm{BAB}$ in a measured aliquot $(5 \mathrm{ml}$ each) of the reaction mixture at different intervals of time. Pseudo-first-order rate constants $\left(k^{\prime}\right)$ calculated from $\log [\mathrm{BAB}]$ vs time plots were reproducible to within $\pm 3-5 \%$.

\subsection{Stoichiometry and product analysis}

Varying ratios of $\mathrm{BAB}$ to amino acids were equilibrated at $30^{\circ} \mathrm{C}$ in presence of $0.20 \mathrm{~mol} \mathrm{dm}^{-3} \mathrm{HClO}_{4}$ for $24 \mathrm{~h}$. Estimation of the unreacted BAB showed a $1: 2$ stoichiometry for both the amino acids.

$$
\begin{aligned}
\mathrm{RCH}\left(\mathrm{NH}_{2}\right) \mathrm{COOH}+2 \mathrm{PhSO}_{2} \mathrm{NBrNa}+2 \mathrm{H}_{2} \mathrm{O} \rightarrow & \mathrm{RCOOH}+\mathrm{NH}_{3}+\mathrm{CO}_{2} \\
& +2 \mathrm{PhSO}_{2} \mathrm{NH}_{2}+2 \mathrm{Na}^{+}+2 \mathrm{Br}^{-}
\end{aligned}
$$

Here $\mathrm{R}=\left(\mathrm{CH}_{2}\right)_{2} \mathrm{COOH}-$ for $\mathrm{Glu}$ and $\mathrm{CH}_{2} \mathrm{COOH}-$ for Asp.

The benzensulphonamide $\left(\mathrm{PhSO}_{2} \mathrm{NH}_{2}\right)$, was recrytallized from dichloromethane/ petroleum ether (m.p. $=149-150^{\circ} \mathrm{C}$, lit. m.p. $=150-152^{\circ} \mathrm{C}$ ). An $R_{f}$ value of 0.36 was 
determined from TLC using $\mathrm{CH}_{2} \mathrm{Cl}_{2}+\mathrm{CHCl}_{3},(7: 3, v / v)$ as the solvent system and iodine as the spray reagent. Ammonia was quantitatively estimated by the microkjeldahl procedure ${ }^{11}$. Dicarboxylic acids, succinic and malonic acids were detected by spot tests ${ }^{12}$ and then by TLC. The liberated $\mathrm{CO}_{2}$ was detected by the lime water test. The reaction mixture failed to initiate polymerization of aqueous acrylamide solution, indicating the absence of free radicals.

\section{Results}

The kinetics of oxidation of glutamic and aspartic acids by $\mathrm{BAB}$ were investigated at several initial concentrations of the reactants in $\mathrm{HClO}_{4}$ medium.

Under pseudo-first-order conditions of [substrate $]_{\mathrm{o}} \gg[\mathrm{BAB}]_{\mathrm{o}}$ at constant [substrate $]_{\mathrm{o}}$, $\left[\mathrm{HClO}_{4}\right],\left[\mathrm{NaClO}_{4}\right]$ and temperature, plots of $\log [\mathrm{BAB}]$ vs time were linear $(r>0.9944)$ indicating first-order dependence of rate on $[\mathrm{BAB}]_{0}$. Furthermore, the rate constant did not change with change in $[\mathrm{BAB}]_{\mathrm{o}}$, confirming first-order dependence on $[\mathrm{BAB}]_{\mathrm{o}}$. Increase in [substrate $]_{\mathrm{o}}$ increased the rate (table 1). Plots of $\log k^{\prime}$ vs $\log [\text { substrate }]_{\mathrm{o}}$ were linear $(r>0.9989)$ with unit slopes, showing first-order dependence of the rate on [substrate] $]_{\circ}$. Further, plots of $k^{\prime}$ vs [substrate] $]_{0}$ were passed through the origin $(r>0.9980)$, confirming first-order dependence on [substrate] $]_{o}$ and the complex formed with oxidant as having transient existence.

The rate decreased with increase in $\left[\mathrm{HClO}_{4}\right]$ (table 1) and plots of $\log k^{\prime}$ vs $\log \left[\mathrm{H}^{+}\right]$ were found to be linear $(r>0.9982)$ with a slope of -1 at $\left[\mathrm{H}^{+}\right]=0.05$ to $0.50 \mathrm{~mol} \mathrm{\textrm {dm } ^ { - 3 }}$ (table1). Further a plot of $k^{\prime}$ vs $1 /\left[\mathrm{H}^{+}\right]$was linear and passed through the origin $(r>0.9892)$ indicating that oxidation occurred only through the acid dependent path under these conditions. At $\left[\mathrm{H}^{+}\right]>0.60 \mathrm{~mol} \mathrm{dm}^{-3}$, the rate levelled off indicating zeroorder dependence on $\left[\mathrm{H}^{+}\right]$(table 1). Under these conditions, the rate was fractional order in [substrate] $]_{0}$, since plots of $\log k^{\prime}$ vs $\log [\text { substrate] }]_{\text {o }}$ were linear $(r>0.9887)$, with slopes of 0.38 and 0.50 respectively, for Glu and Asp (table 1).

Addition of halide ions in the form of $\mathrm{NaCl}$ or $\mathrm{NaBr}\left(5 \times 10^{-3}-3 \times 10^{-2} \mathrm{~mol} \mathrm{dm}^{-3}\right)$ or the reaction product, $\mathrm{PhSO}_{2} \mathrm{NH}_{2}\left(5 \times 10^{-3}-5 \times 10^{-2} \mathrm{~mol} \mathrm{dm}^{-3}\right)$, had no effect on the rate. Similarly variation of ionic strength from 0.2 to $1.2 \mathrm{~mol} \mathrm{dm}{ }^{-3}$ by adding $\mathrm{NaClO}_{4}$ did not affect the rate. Addition of methanol to the reaction mixture $(0-40 \% v / v)$ increased the rate, and plots of $\log k^{\prime}$ vs $1 / D$, where $D$ is the dielectric constant of the medium were linear $(r>0.9925)$ with a positive slope. Blank experiments showed that methanol was very slightly oxidized $(<2 \%)$ by $\mathrm{BAB}$ under the experimental conditions. This was taken into account in the calculation of net reaction rate constant for the oxidation of amino acids each time.

The reaction was studied at different temperatures (288-308 K), keeping other experimental conditions constant. From the Arrhenius plots of $\log k^{\prime}$ vs $1 / T(r>0.9980)$, activation energy and other thermodynamic parameters for Glu and Asp were found to be $E_{a}=54 \cdot 6,41 \cdot 9 ; \Delta H^{\#}=52 \cdot 1,35 \cdot 8 ; \Delta G^{\#}=92 \cdot 1,88.5 \mathrm{~kJ} \mathrm{~mol}^{-1}$ and $\Delta S^{\#}=-134.3$, $-176.6, \mathrm{~J} \mathrm{~K}^{-1} \mathrm{~mol}^{-1}$ respectively. Studies on the rate in $\mathrm{D}_{2} \mathrm{O}$ medium for Glu and Asp revealed that $k^{\prime}\left(\mathrm{H}_{2} \mathrm{O}\right)$ is $4.54 \times 10^{-4} \mathrm{~s}^{-1}, 7.20 \times 10^{-4} \mathrm{~s}^{-1}$ and $k^{\prime}\left(\mathrm{D}_{2} \mathrm{O}\right)$ is $2.90 \times 10^{-4} \mathrm{~s}^{-1}$, $4.54 \times 10^{-4} \mathrm{~s}^{-1}$ respectively. The solvent isotope effect $k^{\prime}\left(\mathrm{H}_{2} \mathrm{O}\right) / k^{\prime}\left(\mathrm{D}_{2} \mathrm{O}\right)=1.57$ and 1.59 for the two amino acids. Proton inventory studies were made in $\mathrm{H}_{2} \mathrm{O}-\mathrm{D}_{2} \mathrm{O}$ mixtures for both the amino acids and the results are shown in table 2 . The corresponding proton inventory plots for the rate constant $k_{n}^{\prime}$ in a solvent mixture containing deuterium atom fraction $n$ are given in figure 1 . 
Table 1. Effect of varying concentrations of substrate and acid on the reaction rate. $[\mathrm{BAB}]_{\mathrm{o}}=8.0 \times 10^{-4} \mathrm{~mol} \mathrm{dm}^{-3}, I=1 \cdot 0 \mathrm{~mol} \mathrm{\textrm {dm } ^ { - 3 }}$, temperature $=30^{\circ} \mathrm{C}$

\begin{tabular}{|c|c|c|c|}
\hline \multirow{2}{*}{$\begin{array}{l}\left.10^{2} \text { [amino acid }\right] \\
\left(\mathrm{mol} \mathrm{dm}^{-3}\right)\end{array}$} & \multirow{2}{*}{$\begin{array}{l}10\left[\mathrm{HClO}_{4}\right] \\
\left(\mathrm{mol} \mathrm{dm}^{-3}\right)\end{array}$} & \multicolumn{2}{|c|}{$k^{\prime} \times 10^{4}\left(\mathrm{~s}^{-1}\right)$} \\
\hline & & Glu & Asp \\
\hline 1.0 & $2 \cdot 0$ & $1.06(1.05)$ & $1.86(1.22)$ \\
\hline $2 \cdot 0$ & $2 \cdot 0$ & $2.20(1.35)$ & $3.58(1.82)$ \\
\hline $4 \cdot 0$ & $2 \cdot 0$ & $4.54(1.70)$ & $7.20(2.64)$ \\
\hline $10 \cdot 0$ & $2 \cdot 0$ & $9.72(2.56)$ & $16 \cdot 2(3 \cdot 85)$ \\
\hline $16 \cdot 0$ & $2 \cdot 0$ & $15 \cdot 8(3 \cdot 72)$ & $23 \cdot 7(5 \cdot 50)$ \\
\hline $4 \cdot 0$ & $0 \cdot 5$ & $17 \cdot 6$ & $28 \cdot 6$ \\
\hline $4 \cdot 0$ & 1.0 & $9 \cdot 24$ & $14 \cdot 7$ \\
\hline $4 \cdot 0$ & $2 \cdot 0$ & $4 \cdot 54$ & $7 \cdot 20$ \\
\hline $4 \cdot 0$ & $3 \cdot 0$ & $3 \cdot 18$ & $4 \cdot 85$ \\
\hline $4 \cdot 0$ & $4 \cdot 0$ & $2 \cdot 30$ & $3 \cdot 74$ \\
\hline $4 \cdot 0$ & $5 \cdot 0$ & 1.74 & $2 \cdot 55$ \\
\hline $4 \cdot 0$ & $6 \cdot 0$ & 1.89 & $2 \cdot 50$ \\
\hline $4 \cdot 0$ & $7 \cdot 0$ & $1 \cdot 70$ & $2 \cdot 64$ \\
\hline $4 \cdot 0$ & $8 \cdot 0$ & 1.78 & $2 \cdot 46$ \\
\hline $4 \cdot 0$ & $9 \cdot 0$ & 1.68 & $2 \cdot 42$ \\
\hline
\end{tabular}

Values in parentheses refer to variation of amino acid concentrations at higher $\left[\mathrm{H}^{+}\right]=0.7 \mathrm{~mol} \mathrm{dm}^{-3}$.

Table 2. Proton inventory studies for the oxidation of glutamic and aspartic acids in $\mathrm{H}_{2} \mathrm{O}-\mathrm{D}_{2} \mathrm{O}$ mixtures.

\begin{tabular}{lcc}
{$[\mathrm{BAB}]_{\mathrm{o}}=8.0 \times 10^{-4} \mathrm{~mol} \mathrm{dm}^{-3} ;[\text { substrate }]_{0}=4.0 \times 10^{-2} \mathrm{~mol} \mathrm{dm}^{-3} ;$} \\
{$\left[\mathrm{HClO}_{4}\right]=0.2 \mathrm{~mol} \mathrm{dm}^{-3} ; I=1.0 \mathrm{~mol} \mathrm{dm}^{-3} ;$ temperature $=30^{\circ} \mathrm{C}$} \\
\hline \multirow{2}{*}{$\begin{array}{c}k_{n}^{\prime} \times 10^{4}\left(\mathrm{~s}^{-1}\right) \\
\text { Atom fraction of } \\
\text { deuterium }(n)\end{array}$} & $\mathrm{Glu}$ & Asp \\
\cline { 2 - 3 } 0.000 & 4.54 & 7.20 \\
0.248 & 3.90 & 6.33 \\
0.496 & 3.26 & 5.52 \\
0.744 & 2.97 & 4.80 \\
0.992 & 2.90 & 4.54 \\
\hline
\end{tabular}

\section{Discussion}

The following rate laws are observed for the oxidation of amino acids $(\mathrm{S})$ by BAB in acid medium:

$$
\begin{aligned}
& -\mathrm{d}[\mathrm{BAB}] / \mathrm{d} t=k[\mathrm{BAB}][\mathrm{S}]\left[\mathrm{H}^{+}\right]^{-1}, \text { at low }\left[\mathrm{H}^{+}\right], \\
& -\mathrm{d}[\mathrm{BAB}] / \mathrm{d} t=k[\mathrm{BAB}][\mathrm{S}]^{x}, \text { at high }\left[\mathrm{H}^{+}\right] .
\end{aligned}
$$

Here $x$ is less than one.

Amino acids are known to exist as neutral molecules (S), zwitterions $\left(\mathrm{S}^{\mathrm{o}}\right)$, anions $\left(\mathrm{S}^{-}\right)$ and cations $\left(\mathrm{SH}^{+}\right)$in aqueous solutions and dissociation depends upon the $p \mathrm{H}$ of the medium: 


$$
\mathrm{S}^{-}
$$

anion

$\mathrm{S}^{\mathrm{o}}$
dipolar zwitterion

$\mathrm{SH}^{+}$

cation

(strongly acidic)

It is expected that similar equilibria exist in aqueous solutions of N-metallo- $\mathrm{N}$ haloarylsulphonamides ${ }^{13-16}$. In general, $\mathrm{BAB}$ undergoes a two-electron change in its reactions. The possible oxidizing species in acidified $\mathrm{BAB}$ solutions are $\mathrm{PhSO}_{2} \mathrm{NHBr}$, $\mathrm{PhSO}_{2} \mathrm{NBr}_{2}$ and $\mathrm{HOBr}$. If $\mathrm{PhSO}_{2} \mathrm{NBr}_{2}$ were to be the reactive species, the rate law predicts second-order dependence of rate on $[\mathrm{BAB}]_{\mathrm{o}}$, which is contrary to experimental observations. Further, the hydrolysis of $\mathrm{PhSO}_{2} \mathrm{NHBr}$ is slight ${ }^{16}$ and if $\mathrm{HOBr}$ is primarily involved, a retardation of rate by the added benzenesulphonamide is expected. However, no such effect was noticed. Hardy and Johnston's ${ }^{15}$ calculations on aqueous bromamine- $\mathrm{B}$ solutions in the $p \mathrm{H}$ range $7-13$ have shown that the concentration of the conjugate acid $\mathrm{PhSO}_{2} \mathrm{NHBr}$ is higher when compared with the other species. At $p \mathrm{H} 7, \quad\left[\mathrm{PhSO}_{2} \mathrm{NHBr}\right] \approx 4 \cdot 1 \times 10^{-5} \mathrm{~mol} \mathrm{dm}^{-3}$, while $[\mathrm{HOBr}] \approx 6 \cdot 0 \times$ $10^{-6} \mathrm{~mol} \mathrm{dm}^{-3}$ and $\left[\mathrm{OBr}^{-}\right] \approx 10^{-8} \mathrm{~mol} \mathrm{dm}^{-3}$. Hence $\mathrm{PhSO}_{2} \mathrm{NHBr}$ is the likely oxidizing species which reacts with the substrate. Morris et $a l^{14}$ have determined the $p K a$ of $\mathrm{PhSO}_{2} \mathrm{NHCl}$ as 4.56 (at $25^{\circ} \mathrm{C}$ ) and, if the same value is assumed for the bromine analogue, at the experimental conditions of acidity $\mathrm{BAB}$ would be present as the free acid $\mathrm{PhSO}_{2} \mathrm{NHBr}$. Rate law (2) indicates that unprotonated acid molecule participates in the rate-limiting step (rls). Scheme 1 is proposed to interpret the experimental observations.

From scheme 1 , assuming $K_{2}$ to be a small equilibrium and $K_{2}\left[\mathrm{~S}^{\circ}\right]<1$, rate law (5) can be derived: 


$$
\begin{array}{ll}
\mathrm{SH}^{+} \stackrel{K_{1}}{\mathrm{~S}^{\mathrm{o}}+\mathrm{H}^{+},} & \text {(i) fast } \\
\mathrm{S}^{\mathrm{o}}+\mathrm{PhSO}_{2} \mathrm{NHBr}^{K_{2}} \mathrm{X}, & \text { (ii) slow } \\
\mathrm{X} \stackrel{k_{3}}{\rightarrow} \mathrm{X}^{\prime}, & \text { (iii) slowest and } r l s \\
\mathrm{X}^{\prime}+\mathrm{PhSO}_{2} \mathrm{NHBr} \stackrel{k_{4}}{\rightarrow} \text { products. } & \text { (iv) fast }
\end{array}
$$

\section{Scheme 1.}

$$
\begin{array}{ll}
\mathrm{SH}^{+}+\mathrm{PhSO}_{2} \mathrm{NHBr} & K_{5} \\
\mathrm{X}^{\prime \prime} \stackrel{k_{6}}{\rightarrow} \mathrm{X}^{\prime \prime \prime}, & \text { (i) slow } \\
\mathrm{X}^{\prime \prime \prime}+\mathrm{PhSO}_{2} \mathrm{NHBr} \stackrel{k_{7}}{\rightarrow} \text { products. } & \text { (iii) fast }
\end{array}
$$

Scheme 2.

Here $[\mathrm{BAB}]_{t}$ represents the total $\mathrm{BAB}$ concentration. Equation (5) is in agreement with experimental results, wherein a first-order dependence of rate on [BAB] and [amino acid] and inverse first-order on $\left[\mathrm{H}^{+}\right]$have been noted.

At higher $\left[\mathrm{H}^{+}\right]$, the rate levels off and rate law (3) is obeyed. The substrate species $\mathrm{SH}^{+}$ would then directly interact with $\mathrm{PhSO}_{2} \mathrm{NHBr}$ as in scheme 2:

Scheme 2 leads to rate law (6):

$$
\frac{-\mathrm{d}[\mathrm{BAB}]}{\mathrm{d} t}=\frac{K_{5} k_{6}[\mathrm{BAB}]_{\mathrm{t}}\left[\mathrm{SH}^{+}\right]}{1+K_{5}\left[\mathrm{SH}^{+}\right]} .
$$

Equation (6) predicts fractional order in [substrate $]_{\mathrm{o}}$ and first-order in $[\mathrm{BAB}]_{\mathrm{o}}$ as has been observed experimentally. Equation (6) can be transformed into (7):

$$
\frac{1}{k^{\prime}}=\frac{1}{K_{5} k_{6}\left[\mathrm{SH}^{+}\right]}+\frac{1}{k_{6}} \text {. }
$$

From slope and intercept of double reciprocal plots $(r>0.9865)$, values of $K_{5}$ and $10^{5} k_{6}$ (formation and decomposition constants of $\mathrm{X}^{\prime \prime}$ ) determined are 85.4 (Glu), 77.1 (Asp) $\mathrm{dm}^{3} \mathrm{~mol}^{-1}$, and $6.9(\mathrm{Glu}), 8.8(\mathrm{Asp}) \mathrm{s}^{-1}$ respectively. Detailed mechanistic interpretation of schemes 1 and 2 are shown in schemes 3 and 4 .

Solvent isotope studies in $\mathrm{D}_{2} \mathrm{O}$ medium show a retardation of rate as expected, since $\mathrm{D}_{3} \mathrm{O}^{+}$is a stronger acid than the hydronium ion ${ }^{17}$. Hence, the proposed mechanism is also supported by the decrease in rate in $\mathrm{D}_{2} \mathrm{O}$ medium. Proton inventory studies in $\mathrm{H}_{2} \mathrm{O}-\mathrm{D}_{2} \mathrm{O}$ mixtures could throw light on the nature of the transition state. Dependence of the rate constant $\left(k_{n}^{\prime}\right)$ on $n$, the atom fraction of deuterium in a solvent mixture of $\mathrm{H}_{2} \mathrm{O}-\mathrm{D}_{2} \mathrm{O}$ is given ${ }^{18,19}$, by a form of Gross-Butler equation as in 


$$
\frac{k_{o}^{\prime}}{k_{n}^{\prime}}=\pi^{\mathrm{TS}}\left(1-n+n \phi_{i}\right) / \pi^{\mathrm{RS}}\left(1-n+n \phi_{i}\right),
$$

where $\phi_{i}$ and $\phi_{j}$ are the isotopic fractionation factors for isotopically exchangeable hydrogen sites in the transition state (TS) and in the ground or reactant state (RS) respectively. Equation (8) permits the evaluation of $\phi_{i}$ when the value of $\phi_{j}$ is known. However, the curvature of proton inventory plots could reflect the number of exchangeable protons in the reaction ${ }^{20}$. Plots of $k_{n}^{\prime}$ vs $n$ (figure 1 ; table 2) are curves in the present case and these, in comparison with the standard curves ${ }^{20}$, indicate the involvement of a single proton or $\mathrm{H}-\mathrm{D}$ exchange in the reaction sequence. This proton

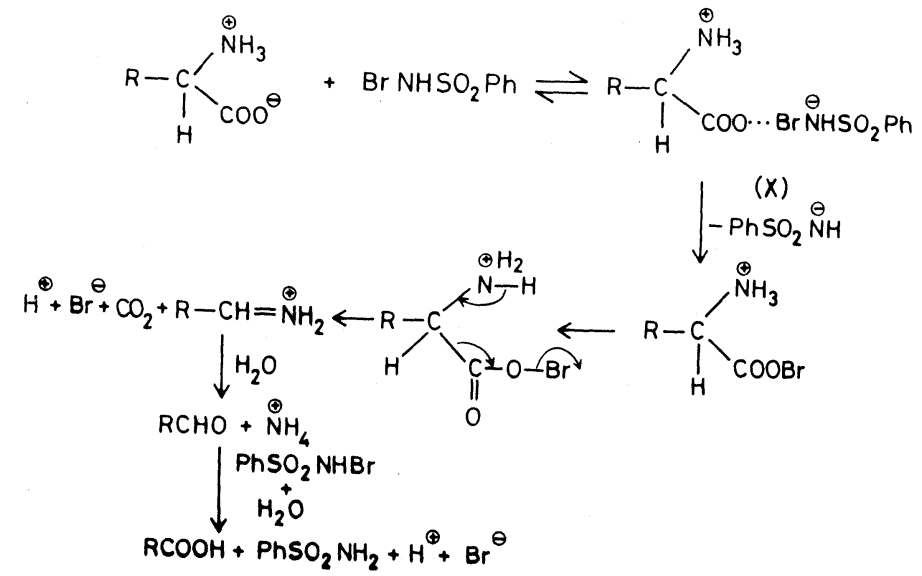

Scheme 3.

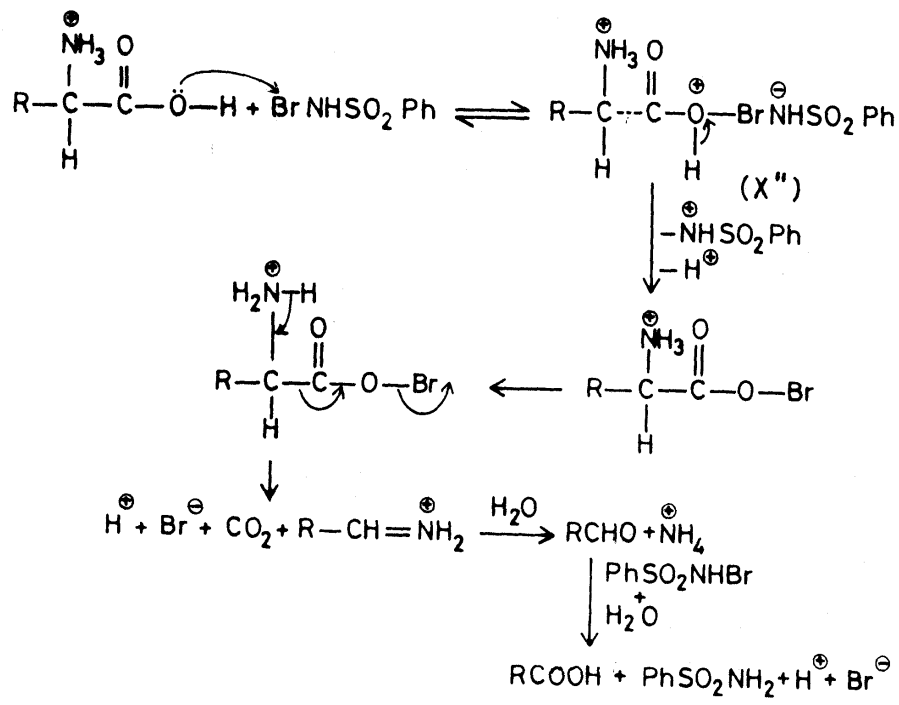

Scheme 4. 
exchange is indicative of the participation of hydrogen ions in the formation of the transition state.

The reaction product benzenesulphonamide $\left(\mathrm{PhSO}_{2} \mathrm{NH}_{2}\right)$ does not influence the rate, showing that it is not involved in pre-equilibrium. Variation of the ionic strength of the medium does not alter the rate indicating that non-ionic species are involved in the ratelimiting step. Addition of halide ions has no effect on the rate indicating that no interhalogen or free bromine is formed and $\mathrm{PhSO}_{2} \mathrm{NHBr}$ interacts directly with the substrate species. The dielectric effect is found to be positive, with the rate of reaction increasing in a solvent mixture of lower polarity than water ${ }^{21}$. Hence, the transition state formed is less polar and there is charge dispersal under these conditions. All these observations confirm the proposed mechanism.

The proposed mechanism is also supported by the moderate values of energy of activation and other thermodynamic parameters. The large negative $\Delta S^{\#}$ values indicate the formation of the compact activated complex with fewer degrees of freedom. The near constancy of the free energy of activation points to a common mechanism for the oxidation of both the amino acids. The presence of an intervening methylene group as in glutamic acid could lead to a diminution of the $+\mathrm{I}$ effect which may be responsible for the difference in the rates of oxidation of these two amino acids.

\section{Acknowledgement}

One of the authors (NV) thanks the Principal and the Management of Jyoti Nivas College, Bangalore for encouragement and also the University Grants Commission, New Delhi for a fellowship.

\section{References}

1. Campbell M M and Johnson G 1978 Chem. Rev. 7865

2. Banerji K K, Jayaram B and Mahadevappa D S 1987 J. Sci. Ind. Res. 4665

3. Puttaswamy, Anuradha T M, Ramachandrappa R and Gowda N M M 2000 Int. J. Chem. Kinet. 32221

4. Kothari S and Banerji K K 1985 Can. J. Chem. 632726

5. Venkatesha B M, Ananda S and Mahadevappa D S 1992 Indian J. Chem. A32 814

6. Puttaswamy and Ramachandrappa R 1999 Transition Met. Chem. 2452

7. Mahadevappa D S, Ananda S, Murthy A S A and Rangappa K S 1984 Indian J. Chem. A23 17

8. Gowda B T, Sherigara B S, Mahadevappa D S and Rangappa K S 1985 Indian J. Chem. A24 932

9. Ahmed M S and Mahadevappa D S 1980 Talanta 27669

10. Vogel A I 1958 Quantitative organic analysis (London: Longman Green) p. 708

11. Vogel A I 1978 Quantitative inorganic analysis 4th edn (London: ELBS and Longman) p. 313

12. Feigl F 1956 Spot tests in organic analysis (Amsterdam: Elsevier) p. 120

13. Bishop E and Jennings V J 1958 Talanta 1197

14. Morris J C, Salazar J A and Wineman M A 1948 J. Am. Chem. Soc. 702036

15. Hardy F F and Johnston J P 1973 J. Chem. Soc. Perkin Trans. II 742

16. Pryde B G and Soper F G 1931 J. Chem. Soc. 1514

17. Collins C J and Bowman N S 1970 Isotope effects in chemical reactions (New York: Van Nostrand-Reinhold) p. 267

18. Albery W J and Davies M H 1972 J. Chem. Soc., Faraday Trans. 68167

19. Gopalakrishnan G and Hogg J L 1985 J. Org. Chem. 501206

20. Isaacs N S 1987 Physical organic chemistry (New York: Wiley) p. 275

21. Amis E S 1966 Solvent effects on reaction rates and mechanisms (New York: Academic Press) 